\title{
Effects of Pulsed Electromagnetic Fields on Breast Cancer Cell Line MCF 7 Using Absorption Spectroscopy
}

\author{
DOMINIC Z. ALCANTARA ${ }^{1}$, IAN JERRY S. SOLIMAN ${ }^{1}$, ROMERIC F. POBRE ${ }^{1}$ and RAOUF N.G. NAGUIB ${ }^{2,3}$ \\ ${ }^{1}$ Optics and Instrumentation Physics Laboratory, Physics Department, De La Salle University, Manila, Philippines; \\ ${ }^{2}$ Faculty of Science, Liverpool Hope University, Liverpool, U.K.; \\ ${ }^{3}$ BIOCORE Research \& Consultancy International, Liverpool, U.K.
}

\begin{abstract}
We present an analysis of the effects of pulsed electromagnetic fields (PEMF) with $3.3 \mathrm{MHz}$ carrier frequency and modulated by audio resonant frequencies on the MCF-7 breast cancer cell line in vitro using absorption spectroscopy. This involves a fluorescence dye called PrestoBlue $^{T M}$ Cell Viability Reagent and a spectrophotometry to test the viability of MCF-7 breast cancer cells under different PEMF treatment conditions in terms of the cell absorption values. The DNA molecule of the MCF-7 breast cancer cells has an electric dipole property that renders it sensitive and reactive to applied electromagnetic fields. Resonant frequencies derived from four genes mutated in MCF-7 breast cancer cells [rapamycin-insensitive companion of mammalian target of rapamycin (RICTOR), peroxisome proliferator-activated receptor (PPARG), Nijmegen breakage syndrome $1(N B N)$ and checkpoint kinase 2 (CHEK2)] were applied in generating square pulsed electromagnetic waves. Effects were monitored through measurement of absorption of the samples with PrestoBlue ${ }^{T M}$, and the significance of the treatment was determined using the t-test. There was a significant effect on MCF-7 cells after treatment with PEMF at the resonant frequencies of the following genes for specific durations of exposure: RICTOR for $10 \mathrm{~min}$, PPARG for 10 min, NBN for $15 \mathrm{~min}$, and CHEK2 for $5 \mathrm{~min}$.
\end{abstract}

This study sought to investigate the use of an alternative approach - pulsed electromagnetic fields - to common breast cancer treatment protocols as a therapy modality for breast cancer cells, through the use of breast cancer cell line MCF7 (1). The study was in support of a non-invasive, safer,

Correspondence to: Raouf Naguib, Woodlands, Waverley Edge, Bubbenhall, Warwickshire CV8 3LW, U.K. E-mail: naguibr@ hope.ac.uk; r.naguib@biocoreinternational.com

Key Words: Breast cancer, gene mutation, pulsed electromagnetic fields, spectroscopy, PrestoBlueT ${ }^{\mathrm{TM}}$. more affordable, more accessible and more convenient type of treatment that would be able to achieve acceptable results in treating breast cancer.

Pulsed electromagnetic fields have already made some landmark contributions in telecommunications and health science diagnosis (2). In the early 1960s, the European Union started to make use of electromagnetic therapeutic systems for health conditions such as inflamed nerves and muscles. In some cases, low frequency signals were used to treat delayed bone fractures (3); these are the types of fractures that take an exceptionally long time to heal. With the advent of using low frequency signals, the methodology eventually developed into what is now termed pulsed electromagnetic field therapy. Although the name itself has been reserved for non-cancer treatment, the principle and physics behind the equipment used are similar to those used here.

Objective of the study. The objective of the study was to explore the effects, be it cell proliferation or cell death, of pulsed electromagnetic fields on the MCF-7 breast cancer cell line. A cell line is a cell culture developed from a single cell and therefore consisting of cells with a uniform genetic makeup. The research applied different treatment parameters, such as exposure time and specific frequencies, which could affect either cell proliferation or cell death of MCF-7 breast cancer cells due to pulsed electromagnetic fields. The collection of data consisted of a control cell group and a treated cell group, which were correlated with a standard $t$-test to mathematically prove any significant effect. Furthermore, using absorption spectroscopy, the study was able to analyse the effects more objectively.

DNA Frequency Theory. The study was based on the DNA Frequency Theory (4) which contends that the DNA could be an informational source of frequencies for use in electrotherapeutic devices. It was found that DNA poses a dipole characteristic, in which there is directionality of charged molecules in the chain. If the DNA chain were unravelled, a positive charge would be observed on one end of a strand and 
a negative charge on the other end. This would mean that DNA has conducting characteristics. When two strands are bonded normally, the charges are aligned in parallel but have opposite polarity. In (5), the polarity of the DNA structure is shown, where the 5' to 3' strand is parallel to the 3' to 5' strand. It was observed that negatively-charged ions pass along the entire length of the chain in a helical manner. This would surmise that the strands are sensitive to the effects of electromagnetic fields. In the realm of radio science, the length of an antenna largely determines how effective it responds to the wavelength energy of an incoming transmission. In a similar fashion, it has been proposed that the length of any piece of DNA could be resonated using the same principle.

Full details of the DNA Frequency Theory can be found in (6) where a simple mathematical procedure was proposed to calculate the frequency of any DNA chain. It indicated that an organism's entire DNA genome could possess a resonant wavelength and frequency related to its total length. The calculation of the resonant frequency of any DNA was found to be $4,526,016.22$. Thus:

$f=4,526,016.22 / b$

Eq. 1

where $f=$ the total resonant frequency and $b=\#$ of base pairs in the DNA chain.

However, some computed frequencies cannot be attained, due to device limitations. To overcome this, the frequency can be adjusted to either upper or lower harmonics of the carrier frequency. This effectively means either doubling the wavelength or cutting it in half.

MCF-7 Characteristics. MCF-7 is a breast cancer cell line with a karyotype of 79 to 89 chromosomes (1). It shows ideal characteristics similar to the mammary epithelium, such as being receptive to oestrogen and cytokeratin. Since it is epithelial in form, it has a polygonal shape and a regular formation. Using karyotyping results from (7), MCF-7 exhibits structural abnormalities of its chromosomes, namely, $\mathrm{X}, 1,2,3,5,6,7,8,9,12,13,15,18,19,20$ and 22 . In this study, abnormalities of interest were the following (where $p$ is the short arm and $\mathrm{q}$ is the long arm of the chromosome as outlined in the ideograms of chromosomes 5 and 8 (8)):

A. addition of material to the short arm (p) of chromosome 5 ; B. deletion of material from the short arm (p) of chromosome 3; C. addition of material to the long arm (q) of chromosome 8; D. deletion of material from the long arm (q) of chromosome 22.

The rapamycin-insensitive companion of mammalian target of rapamycin (RICTOR) gene is a part of a protein complex that encodes for signals involving cell growth (9). It is located on the short arm of chromosome 5, specifically on 5 p13.1 (10). Since it is at the site of interest given in A, it may play a role in breast tumour proliferation. This gene has also been correlated in the formation of smooth muscle tumours. It has 136,490 base pairs, the number of which will be essential in calculating the DNA resonant frequency.

The peroxisome proliferator-activated receptor gamma $(P P A R G)$ gene is a protein coding gene (11). It is located on 3 p25.2 which is also the site stated in B. The protein expressed by this gene has been linked to the development of numerous diseases, such as obesity, diabetes and cancer. It has 146,989 base pairs.

The Nijmegen breakage syndrome $1(N B N)$ gene encodes for a protein that is associated with the repair of double strand breaks of DNA (12). It is located on 8q21, which is exactly at the site of the abnormality stated in $\mathrm{C}$ above. An abnormal $N B N$ gene has been found to cause Nijmegen breakage syndrome, a condition that causes slow growth in early childhood. People with this syndrome are shorter than average and have a higher risk of developing several types of cancer, including breast cancer (13). This gene has 69,893 base pairs.

The checkpoint kinase 2 (CHEK2) gene, is a tumour suppressor gene. It is located on $22 q 12.1$, which is exactly at the site of the abnormality stated in D. An inherited abnormal CHEK2 gene can cause Li-Fraumeni syndrome, a condition wherein the patient is susceptible to develop multiple types of cancer, especially breast cancer $(14,15)$. This gene has 54,680 base pairs.

Pulsed electromagnetic field (PEMF). It is known that cells vibrate or oscillate, and all cells have receptors and other proteins that can enact change to their activity and metabolic processes depending on the stimulus. One such stimulus is a PEMF that utilizes Faraday's induction law in stimulating electric current in the target cells. When the PEMF frequency is carefully tuned to the resonant frequency of target cells, they respond by generating an electric current produces substantial heat in the surrounding soft tissues (17). This heat and current are capable of exerting metabolic changes which affect the cell's activities simultaneously. The effects of PEMF can either benefit or damage the cell $(17,18)$. When receptor signalling takes place in the cell by primary messengers (proteins, hormones, amino acids, enzymes and electromagnetic signals), the cell changes its behaviour in a prescribed way and it is directed to perform a certain function, such as the activation of enzymes or even apoptosis. This study was in support for the damaging effect of PEMF on cells, specifically breast cancer cells, and sought to investigate whether DNA can also be targeted by PEMF, since it is also sensitive to radiation.

\section{Materials and Methods}

The methodology was applied in vitro instead of in vivo in order to minimise any complications that may affect the system under study. In order to provide support for the investigation, the in vitro 


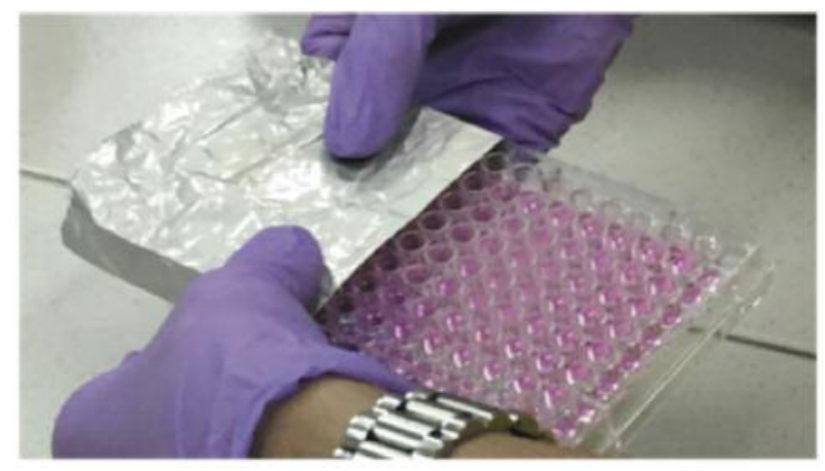

Figure 1. A 96-well plate with breast cancer cells being prepared for exposure to pulsed electromagnetic fields.

methodology of preparing the breast cancer cell samples was modelled using perfusion techniques already prepared by the Molecular Science Unit of De La Salle University, Philippines. In essence, the samples used were a replication of the in vivo phenotype. These samples were equally placed in each well of five 96-microwell plates ( 8 rows $\times 12$ columns) - four for the treatment group and one for the control group - with $25 \mu \mathrm{l}$ of cells placed in each well at approximately $70 \%$ confluence. The cells to be treated with PEMF were placed inside a mesh or Faraday cage that was targeted by modulating resonant frequency propagated by a 3.3 $\mathrm{MHz}$ carrier frequency. To minimise collateral exposure of the neighbouring samples, aluminium foil was placed on the microwell plate to cover it, as shown in Figure 1.

There were three exposure times for each target gene: 5, 10 and $15 \mathrm{~min}$. One microwell plate served to receive one target gene resonant frequency. The plate was divided into three to corresponding with the three different exposure times. For the first microwell plate, the first four columns were treated with PEMF for 5 min using the calculated frequency for the gene. The next four columns were also targeted using the same resonant frequency, but the exposure time was $10 \mathrm{~min}$. Lastly, the final four columns were also targeted using the same resonant frequency, but the duration was 15 minutes.

The DNA resonant frequencies for the targeted genes in MCF-7 were computed using Eq. 1 from the previous section. These are outlined in Table I, where the initial values of the computed frequencies have been increased to the upper harmonics to overcome device limitations.

The PEMF system used in the experiment is a Beam Ray ${ }^{\circledR}$ brand supplied by Frequency Technologies LLC with a built-in radiofrequency amplifier and tuner. PEMF energy is transmitted in an amplitude-modulated electromagnetic waveform through an argon-filled plasma tube that serves as an antenna. It typically emits PEMF in the radiofrequency region oscillating at $3.3 \mathrm{MHz}$ centre frequency, together with its side harmonics modulated by a square wave oscillating at audio frequency, ranging from $20 \mathrm{~Hz}$ to $20 \mathrm{kHz}$. Power output emanating from the plasma tube is about 75 radiofrequency Watts, with an input alternating current electric power usage around 400-600 Watts, operating at 220V AC. During operation, the argon-filled plasma tube is placed inside a Faraday aluminium cage where the microwell plates can be positioned

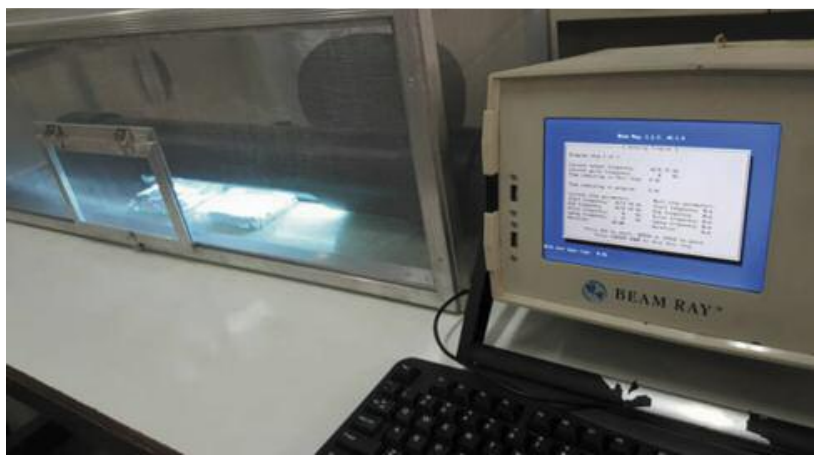

Figure 2. The pulsed electromagnetic field system where the Ar-filled plasma tube is placed inside a Faraday aluminium cage with the microwell plates $2.5 \mathrm{~cm}$ below the plasma tube.

approximately $2.5 \mathrm{~cm}$ below the plasma tube (see Figure 2). Each experiment was carried out using three microwells at a time in a plate covered with an aluminium foil. Since there are 96 microwells in each plate, we performed 32 experiments for every plate under PEMF exposure.

All microwell plates with PEMF-exposed MCF-7 breast cancer cells were treated with $25 \mu \mathrm{l}$ of PrestoBlue ${ }^{\mathrm{TM}}$ (also known as Resazurin) dye, including those of the control group. The dye changes colour depending on cell viability $(19,20)$; the initial blue colour eventually turns into red, purple or pink colour hues, implying that the cells are still alive. If the colour remains blue, the cells are no longer viable. A more quantitative method to determine cell viability is by measuring the absorption values using a spectrophotometer. Following PrestoBlue ${ }^{\mathrm{TM}}$ application, all microwell plates were incubated at $32^{\circ} \mathrm{C}$ for $40 \mathrm{~min}$ to ensure proper viability assessment. They were then placed in the spectrophotometer for absorption reading. The absorption readings were copied, tabulated and saved electronically.

All samples were exposed under the same laboratory conditions (i.e. temperature, mixture of solutions and durations of exposure), therefore the statistical test was used under the assumption of equal variances. A standard statistical $t$-test followed, and the level of confidence was set at $95 \%$ to compare the absorption values between the control and treated groups. Differences between the control and treated cells were considered significant at $p<0.05$.

\section{Results and Discussion}

The absorption values of the control were used as the standard. As mentioned above, wells with absorption values significantly below the controls were considered dead (not viable), whereas those with values equal or above the controls were considered viable (alive). The absorption values for MCF-7 cells treated with RICTOR, PPARG, NBN and CHEK2 gene resonant frequencies are shown in Figure 3.

The results are outlined in Tables II-V for each of the genes, respectively, where a significant change with respect to the control meant a decrease in cell viability (cell death) and a negative $t$-value implied an increase in cell proliferation. 
A

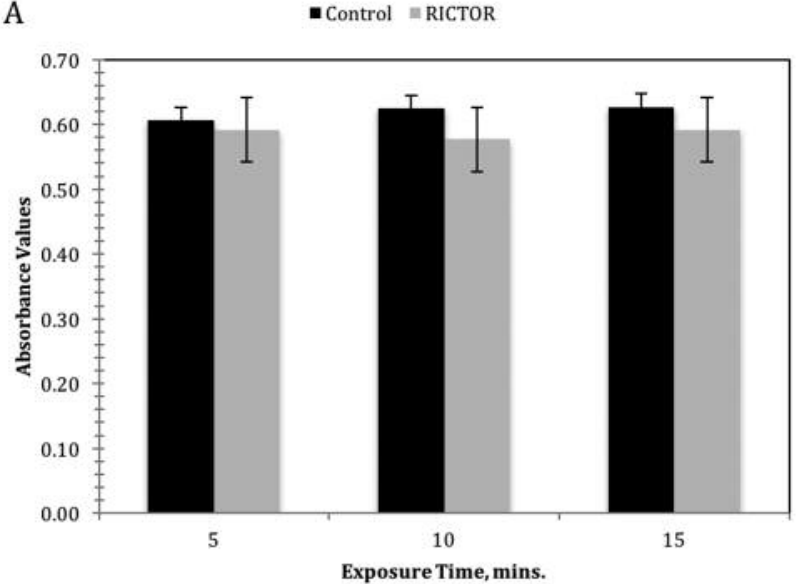

B

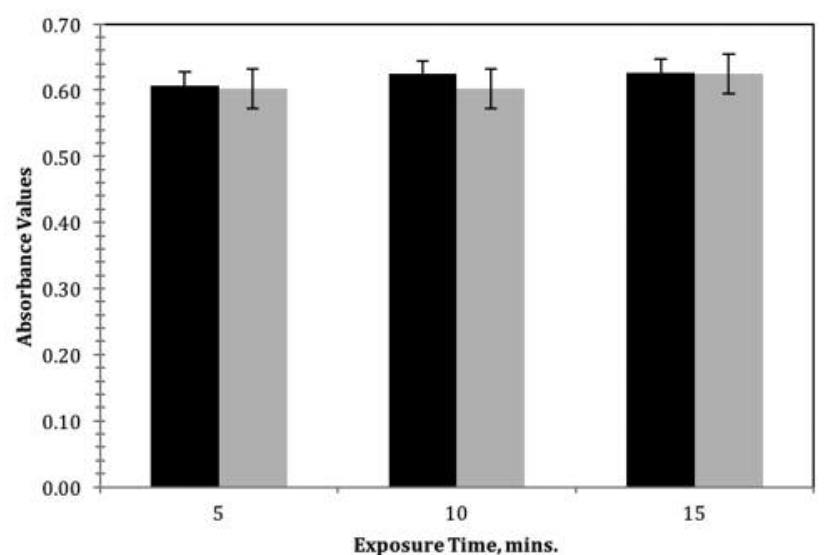

C

- Control $=$ NBN

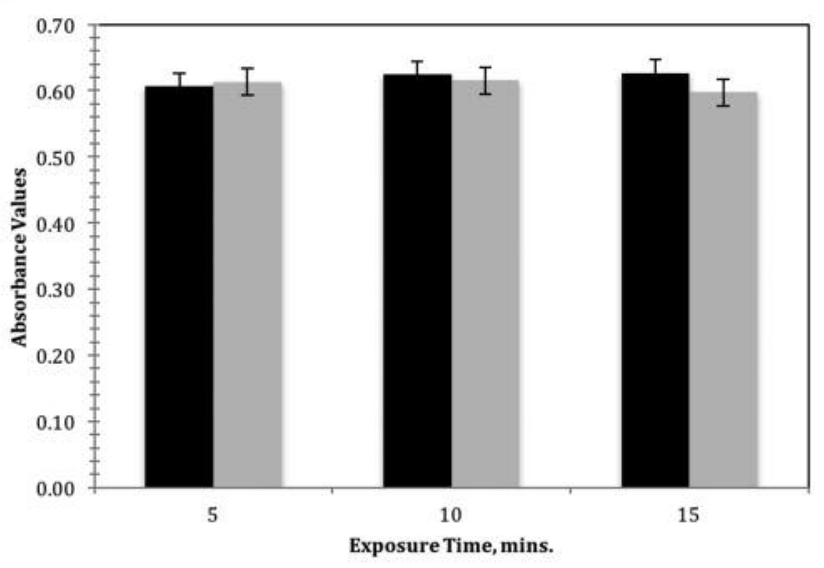

D

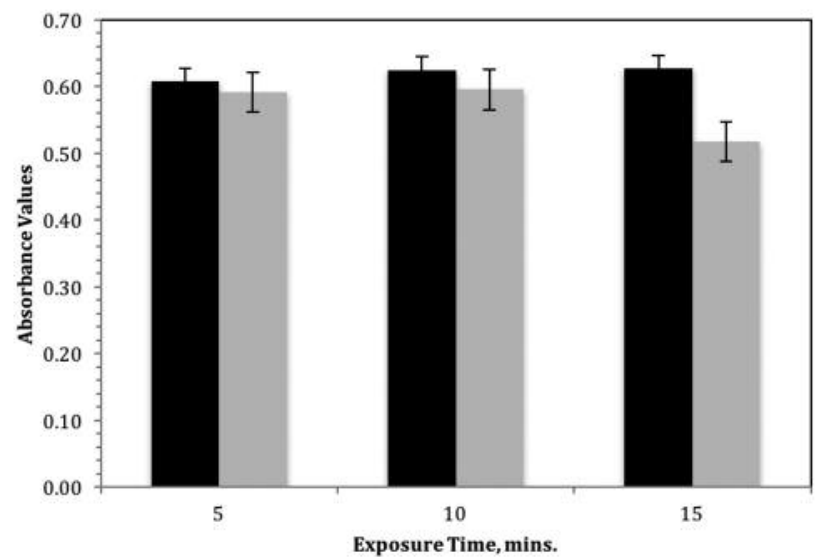

Figure 3. Absorption values for cell cultures treated at resonant frequencies of the rapamycin-insensitive companion of mammalian target of rapamycin $(R I C T O R)(A)$, peroxisome proliferator-activated receptor (PPARG) $(B)$, Nijmegen breakage syndrome $1(N B N)(C)$ and checkpoint kinase 2 (CHEK2) (D) genes.

Table I. Computed DNA resonant frequencies.

\begin{tabular}{lcccc}
\hline $\begin{array}{l}\text { Encoded protein } \\
\text { (target gene location) }\end{array}$ & $\begin{array}{c}\text { No. of DNA } \\
\text { base pairs }\end{array}$ & $\begin{array}{c}\text { Computed DNA resonant } \\
\text { frequency (Hz) }\end{array}$ & $\begin{array}{c}\text { Resonant frequency in } \\
\text { upper harmonics (Hz) }\end{array}$ & nth Harmonic \\
\hline RICTOR (5p13.1) & 136,490 & 33.16 & $2,122.24$ & 64 th \\
PPARG (3p25.2) & 146,989 & 30.79 & $1,970.56$ & 64 th \\
NBN (8q21) & 69,893 & 64.76 & $2,072.32$ & 32 nd \\
CHEK2 (22q12.1) & 54,680 & 82.77 & $2,648.64$ & $32 \mathrm{nd}$ \\
\hline
\end{tabular}

Figure 3 shows that MCF-7 cell viability decrease after $5 \mathrm{~min}$ of PEMF exposure with the RICTOR resonant frequency. The $P P A R G$ gene showed an interesting effect of its resonant frequency. The breast cancer cell absorption values were significantly lower only after the 10-min exposure. Below or beyond this duration there was insignificant effect on cell viability. This indicates that the optimal exposure is $10 \mathrm{~min}$ with the resonant frequency of the $P P A R G$ gene, if the target effect is cell death. Treatment with the resonant frequency for the $N B N$ gene showed interesting 
Table II. Two-sample t-test assuming equal variances for the rapamycin-insensitive companion of mammalian target of rapamycin (RICTOR) gene. Significance was accepted at a value of $p<0.05$.

\begin{tabular}{|c|c|c|c|c|c|c|}
\hline \multirow{2}{*}{$\begin{array}{l}\text { Exposure duration } \\
\text { Variable }\end{array}$} & \multicolumn{2}{|c|}{5 Minutes } & \multicolumn{2}{|c|}{10 Minutes } & \multicolumn{2}{|c|}{15 Minutes } \\
\hline & Control & Dependent & Control & Dependent & Control & Dependent \\
\hline Mean & 0.606844 & 0.620125 & 0.624016 & 0.5782188 & 0.626734 & 0.591531 \\
\hline Pooled variance & 0.0048214 & & 0.00039 & & 0.000120 & \\
\hline Observations & 32 & 32 & 32 & 32 & 32 & 32 \\
\hline$t$ Stat & -0.540998 & & 6.525117 & & 9.092827 & \\
\hline$p$-Value $(\mathrm{T} \leq \mathrm{t})$ one-tail & $0.29625 \mathrm{~s}$ & & $1.622 \mathrm{E}-07$ & & $1.996 \mathrm{E}-10$ & \\
\hline$p$-Value $(\mathrm{T} \leq \mathrm{t})$ two-tail & 0.592504 & & $3.245 \mathrm{E}-07$ & & $3.993 \mathrm{E}-10$ & \\
\hline
\end{tabular}

Table III. Two-sample t-test assuming equal variances for the peroxisome proliferator-activated receptor (PPARG) gene. Significance was accepted at a value of $p<0.05$.

\begin{tabular}{|c|c|c|c|c|c|c|}
\hline \multirow{2}{*}{$\begin{array}{l}\text { Exposure duration } \\
\text { Variable }\end{array}$} & \multicolumn{2}{|c|}{5 Minutes } & \multicolumn{2}{|c|}{10 Minutes } & \multicolumn{2}{|c|}{15 Minutes } \\
\hline & Control & Dependent & Control & Dependent & Control & Dependent \\
\hline Mean & 0.606844 & 0.603552 & 0.624016 & 0.602500 & 0.626734 & 0.624719 \\
\hline Pooled variance & $5.03 \mathrm{E}-05$ & & 0.000182 & & 0.001553 & \\
\hline Observations & 32 & 32 & 32 & 32 & 32 & 32 \\
\hline t Stat & 1.312609 & & 4.515842 & & 0.144656 & \\
\hline $\mathrm{p}$-Value $(\mathrm{T} \leq \mathrm{t})$ one-tail & 0.099634 & & $4.55 \mathrm{E}-05$ & & 0.442975 & \\
\hline $\mathrm{p}$-Value $(\mathrm{T} \leq \mathrm{t})$ two-tail & 0.199268 & & $9.10 \mathrm{E}-05$ & & 0.885950 & \\
\hline
\end{tabular}

Table IV. Two-sample t-test assuming equal variances for the Nijmegen breakage syndrome 1 (NBN) gene. Significance was accepted at a value of $p<0.05$.

\begin{tabular}{|c|c|c|c|c|c|c|}
\hline \multirow{2}{*}{$\begin{array}{l}\text { Exposure duration } \\
\text { Variable }\end{array}$} & \multicolumn{2}{|c|}{5 Minutes } & \multicolumn{2}{|c|}{10 Minutes } & \multicolumn{2}{|c|}{15 Minutes } \\
\hline & Control & Dependent & Control & Dependent & Control & Dependent \\
\hline Mean & 0.606844 & 0.613406 & 0.624016 & 0.615312 & 0.626734 & 0.597203 \\
\hline Pooled variance & 0.000297 & & 0.000148 & & $7.57 \mathrm{E}-05$ & \\
\hline Observations & 32 & 32 & 32 & 32 & 32 & 32 \\
\hline$t$ Stat & -1.077355 & & 2.025462 & & 9.596555 & \\
\hline$p$-Value ( $\mathrm{T} \leq \mathrm{t}$ ) one-tail & 0.144954 & & 0.025898 & & $5.91 \mathrm{E}-11$ & \\
\hline$p$-Value (Tst) two-tail & 0.289909 & & 0.051796 & & $1.18 \mathrm{E}-10$ & \\
\hline
\end{tabular}

Table V. Two-sample t-test assuming equal variances for the checkpoint kinase 2 (CHEK2) gene. Significance was accepted at a value of p<0.05.

\begin{tabular}{|c|c|c|c|c|c|c|}
\hline \multirow{2}{*}{$\begin{array}{l}\text { Exposure duration } \\
\text { Variable }\end{array}$} & \multicolumn{2}{|c|}{5 Minutes } & \multicolumn{2}{|c|}{10 Minutes } & \multicolumn{2}{|c|}{15 Minutes } \\
\hline & Control & Dependent & Control & Dependent & Control & Dependent \\
\hline Mean & 0.60684 & 0.591344 & 0.624016 & 0.595203 & 0.626734 & 0.517453 \\
\hline Pooled variance & $5.8307 \mathrm{E}-05$ & & 0.000230 & & 0.000348 & \\
\hline Observations & 32 & 32 & 32 & 32 & 32 & 32 \\
\hline$t$ Stat & 5.741366 & & 5.376790 & & 16.562768 & \\
\hline$p$-Value (Tst) one-tail & $1.43 \mathrm{E}-06$ & & $4.01 \mathrm{E}-06$ & & $6.11 \mathrm{E}-17$ & \\
\hline$p$-Value ( $\mathrm{T} \leq \mathrm{t}$ ) two-tail & $2.87 \mathrm{E}-06$ & & $8.03 \mathrm{E}-06$ & & $1.22 \mathrm{E}-16$ & \\
\hline
\end{tabular}


results. For the 5- and 10-min durations, there was no significant effect on cell viability. Remarkably, only the 15-min duration significantly reduced cell viability. Finally, using the resonant frequency for the CHEK2 gene, a significant reduction of cell viability was shown for all durations. As the exposure time increased, an inverse relationship between duration of PEMF exposure at the CHEK2 resonant frequency with cell viability was established.

The value of this research is based on the premise that, as medical research advances, gradually increasing specific and therapeutic modalities emerge from physics, biology and engineering innovations (e.g. proton therapy, intensity modulated radiotherapy, radiofrequency therapy, radiation therapy, and stem cell therapy). In spite of these different innovations, breast cancer remains the leading cancer diagnosed in female patients.

The common treatment protocols in breast cancer are surgery, external beam radiation therapy, chemotherapy, hormone therapy, targeted therapy, immunotherapy and bone-directed therapy; most of which have several sideeffects. Even with such advanced methods, some cancer cells remain resilient and may even lead to metastasis. Furthermore, many sectors of the population, especially those in developing countries, have an inadequate level of healthcare services due to factors affecting their circumstances, such as financial incapability and lack of access to quality and affordable medical care (21). As mentioned previously, we believe that the application of this approach supports a non-invasive, safer, more affordable, more accessible and more convenient type of treatment that would be able to achieve acceptable results in treating breast cancer.

\section{Conclusion}

Four mutated genes in the MCF-7 breast cancer cell line were targeted and their resonant frequencies computed using the equation provided by the DNA Frequency Theory. The frequencies were emitted using a pulsed electromagnetic field machine that was amplitude-modulated. Targeting of each gene led to results that indicate the existence of an optimal exposure time to a specific radiofrequency in order to reduce cell viability. Although cell proliferation was observed in a few samples, the $t$-test proved that these were insignificant in the overall results.

Overall, the different frequencies used imply that there is no relationship between increasing the radiofrequency values and reduction of cell viability. This is attributed to the fact that the resonant frequency of $2,072.32 \mathrm{~Hz}$ for the $N B N$ gene had a more significant effect than that for PPARG $(1,970.56 \mathrm{~Hz})$, despite being higher. In other words, there is a specific frequency that must be used in order for cell viability to be affected.
In essence, the CHEK2 gene is an ideal target for producing significant cell death of the MCF-7 breast cancer cell line. This is as a result of its resonant frequency yielding most cell death.

For further research, it is recommended that other genes should be targeted, aside from the ones used here. This is in order to observe whether more effective resonant frequencies could be used. It is also recommended to use different harmonics of resonant frequencies to identify any significant changes in cell viability. Each resonant frequency has different effects on MCF-7 breast cancer cells, at different exposure times, which necessitates further analysis using a genotoxicity test. This will result in a better understanding of the different mechanisms involved in more effectively debilitating MCF-7 breast cancer cells.

\section{Acknowledgements}

The Authors wish to extend their gratitude to Mr. Glenn Oyong for facilitating the culture and growth of the MCF-7 breast cancer cell line and the preparation of the cytotoxicity test at the Molecular Science Unit of Center Natural Sciences and Environmental Research (CENSER) of De La Salle University. They also wish to thank Dr. Ann C. Alvarez of Healing Leaves Clinic and Wellness Center for providing access to her PEMF system in the conduct of our experiment. Finally, the Authors would like to express their gratitude to the De La Salle University Science Foundation for the support they extended in the publication of the paper.

\section{References}

1 Comşa Ş, Cimpean AM and Raica M: The story of MCF-7 breast cancer cell line: 40 years of experience in research. Anticancer Res 35(6): 3147-3154, 2015.

2 Martin CJ and Sutton DG (eds.): Practical radiation protection in healthcare. USA: Oxford University Press, 2015.

3 Cook JJ, Summers NJ and Cook EA: Healing in the new millennium: Bone stimulators: An overview of where we've been and where we may be heading. Clin Podiatr Med Surg 32(1): 4559, 2015.

4 Boehm CA: A brief summary of the DNA-derived frequency theory. Online, available from: <http://www.introductiontorife. com/refandres/files/private/Summary\%20-\%20DNA-derived\% 20Frequency\%20Theory\%20-\%20Boehm.pdf>, Accessed May $15,2017$.

5 Moran L: On the handedness of DNA. Online, available from: <http://sandwalk.blogspot.com/2015/03/on-handedness-ofdna.html>, Accessed April 19, 2017.

6 Boehm CA: Methods for determining therapeutic resonant frequencies. US. Patent No. 7, 280, 874, 2007.

7 American Type Culture Collection: Thawing, propagating, and cryopreserving protocol: MCF-7 breast adenocarcinoma. Physical Sciences-Oncology Center Network Bioresource Core Facility, 2012.

8 National Center for Biotechnology Information: Online, available from <https://www.ncbi.nlm.nih.gov/genome/gdv> , Accessed March 23, 2017. 
9 Sarbassov DD, Ali SM, Kim DH, Guertin DA, Latek RR, Erdjument-Bromage H, Tempst P and Sabatini DM (2004): RICTOR, a novel binding partner of mTOR, defines a rapamycin-insensitive and raptor-independent pathway that regulates the cytoskeleton. Curr Biol 14(14): 1296-1302, 2004.

10 European Bioinformatics Institute: Gene \& protein summary for RICTOR. Online, available from: <http://www.ebi.ac.uk/s4 /summary/molecular?term=RICTOR\&classification=9606>, Accessed February 12, 2017.

11 Greene ME, Blumberg B, McBride OW, Yi HF, Kronquist K, Kwan K, Hsieh L, Greene G and Nimer SD: Isolation of the human peroxisome proliferator activated receptor gamma cDNA: Expression in hematopoietic cells and chromosomal mapping. Gene Expr 4(4-5): 281-299, 1995.

12 Varon R, Vissinga C, Platzer M, Cerosaletti KM, Chrzanowska KH, Saar K, Beckmann G, Seemanová E, Cooper PR, Nowak NJ, Stumm M, Weemaes CM, Gatti RA, Wilson RK, Digweed M, Rosenthal A, Sperling K, Concannon P and Reis A: Nibrin, a novel DNA double-strand break repair protein, is mutated in Nijmegen breakage syndrome. Cell 93(3): 467-476, 1998.

13 Uzunoglu H, Korak T, Ergul E, Uren N, Sazci A, Utkan N., Kargi E, Triyaki Ç and Yirmibesoglu O: Association of the Nibrin gene $(N B N)$ variants with breast cancer. Biomed Rep 4(3): 369-373, 2016.

14 Nevanlinna $\mathrm{H}$ and Bartek J: The CHEK2 gene and inherited breast cancer susceptibility. Oncogene 25(43): 5912-5919, 2006.

15 Offit K and Garber JE: Time to check CHEK2 in families with breast cancer?. J Clin Onc 26(4): 519-520, 2008.

16 Mahmoudinasab H, Sanie-Jahromi F and Saadat M: Effects of extremely low-frequency electromagnetic field on expression levels of some antioxidant genes in human MCF-7 Cells. Mol Biol Res Com 5(2): 77-85, 2016.
17 BioElectronics: Physics \& Clinical Evidence of Pulsed Shortwave Frequency therapy. BioElectronics Corporation, 2012.

18 Bagnato GL, Miceli G, Marino N, Sciortino D and Bagnato GF: Pulsed electromagnetic fields in knee osteoarthritis: A double blind, placebo-controlled, randomized clinical trial. Rheumatology 55(4): 755-762, 2016.

19 Peidaee P, Almansour N, Shukla R and Pirogova E: The cytotoxic effects of low intensity visible and infrared light on human breast cancer (MCF7) cells. Comput Struct Biotechnol J 6(7): 1-8, 2013.

$20 \mathrm{Xu} \mathrm{M}$, McCanna DJ and Sivak JG: Use of the viability reagent PrestoBlue in comparison with AlamarBlue and MTT to assess the viability of human corneal epithelial cells. J Pharmacol Toxicol Methods 71: 1-7, 2015.

21 Glasziou P, Straus S, Brownlee S, Trevena L, Dans L, Guyatt G, Elshaug AG, Janett $R$ and Saini V: Evidence for underuse of effective medical services around the world. Lancet, 2017. doi: 10.1016/S0140-6736(16)30946-1. [Epub ahead of print]

Received May 16, 2017

Revised June 5, 2017

Accepted June 6, 2017 